\title{
Role of Different Molecular Pathways in the Development of Diabetes- Induced Nephropathy
}

\section{Virvikram Sharma* and Sharma PL}

Department of Pharmacology, ISF College of Pharmacy, India

\begin{abstract}
Diabetes mellitus is heterogeneous primary disorder of carbohydrate metabolism with multiple etiologic factors that generally involves absolute or relative insulin deficiency or insulin resistance or both, which results in hyperglycemia. According to $\mathrm{WHO}$ projection; it will be the single largest non-communicable disease worldwide by the year 2025 with the largest diabetic population in India. India leads the world with largest diabetic population thus, being termed the "Diabetes Capital of the World". However, the prevalence of diabetes is consistently increasing, but still an effective treatment is lacking for the management of this epidemic. The uncontrolled and chronic diabetes mellitus often leads to cardiomyopathy, macrovascular complications and microvascular complications that include retinopathy, neuropathy and nephropathy. Diabetic Nephropathy (DN) is mainly characterized by decreased Glomerular Filteration Rate (GFR), excessive deposition of extracellular matrix proteins, thickening of the peripheral glomerular basement membrane, glomerular hypertrophy, tubulointerstitial fibrosis, increased excretion of albumin and decreased creatinine clearance. Formation of Advanced Glycation End-Products (AGEs) activation of Protein Kinase C (PKC), c-Jun N-terminal kinase (JNK), Mitogen Activated Protein Kinases (MAPKs), oxidative stress are the possible molecular mechanisms of DN. Despite many molecular mechanisms, the pathophysiology of DN is not clearly understood and its management is unsatisfactory.
\end{abstract}

Keywords: Diabetes; Nephropathy; Polyol pathway; PKC pathway; Oxidative stress

\section{Introduction}

$\mathrm{DN}$ is a leading cause of end-stage renal failure and its morbidity and mortality is continuously increasing. Diabetic nephropathy is a clinical syndrome characterized by decreased Glomerular Filteration Rate (GFR), excessive deposition of extracellular matrix proteins $[1,2]$ thickening of the peripheral glomerular basement membrane [3], glomerular hypertrophy, tubulointerstitial fibrosis [4], decreased excretion of albumin [5] and decreased creatinine clearance [2] .

\section{Stages of Diabetic Nephropathy}

Approximately $25 \%$ to $40 \%$ of patients with DM 1 ultimately develop Diabetic Nephropathy (DN), which progresses through about five predictable stages.

\section{Stage 1}

Hyperfiltration (Glomerular hypertrophy) (very early diabetes)Increased demand upon the kidneys is indicated by an above-normal Glomerular Filtration Rate (GFR).

\section{Stage 2}

Hyperfiltration (Mesangial expansion / basement memberane thicking (developing diabetes)-The GFR remains elevated or has returned to normal, but glomerular damage has progressed to significant microalbuminuria (small but above-normal level of the protein albumin in the urine). Patients in stage 2 excrete more than $30 \mathrm{mg}$ of albumin in the urine over a 24-hour period. Significant microalbuminuria will progress to End-Stage Renal Disease (ESRD). Therefore, all diabetes patients should be screened for microalbuminuria on a routine (yearly) basis.

\section{Stage 3}

Microallbuminuria (Mesangial sclerosis) (Overt, or dipstickpositive diabetes) - Glomerular damage has progressed to clinical albuminuria. The urine is "dipstick positive," containing more than $300 \mathrm{mg}$ of albumin in a 24-hour period. Hypertension (high blood pressure) typically develops during stage 3 .

Stage 4

(Overt-proteinuria Hypertension (Progressive sclerosis) late-stage diabetes)-Glomerular damage continues, with increasing amounts of protein albumin in the urine. The kidneys' filtering ability has begun to decline steadily, and Blood Urea Nitrogen (BUN) and Creatinine (Cr) has begun to increase. The Glomerular Filtration Rate (GFR) decreases about $10 \%$ annually. Almost all patients have hypertension at stage 4 .

\section{Stage 5}

ESRD (Fibrosis/sclerosis) GFR has fallen to approximately 10 milliliters per minute $(<10 \mathrm{~mL} / \mathrm{min})$ and renal replacement therapy (i.e., hemodialysis, peritoneal dialysis, kidney transplantation) is needed [6].

\section{Pathogenesis of Diabetic Nephropathy}

Various pathways like polyol pathway, formation of advanced glycation end products [7], hexosamine pathway [8], protein kinase C pathway [9], growth factors, cytokines [10] and free radicals [11]. MAPK activation, PARP activation have been reported to play an important role in diabetic nephropathy.

*Corresponding author: Virvikram Sharma, Department of Pharmacology, Is College of Pharmacy b-1,665/19d, New Kundan Puri, Civil Lines, Ludhiana Indiana 141001, India; Fax: +91-1636-236564; Tel: 919878903414; E-mail: virvikram76@gmail.com

Received February 05, 2013; Accepted April 28, 2013; Published May 04, 2013

Citation: Sharma V, Sharma PL (2013) Role of Different Molecular Pathways in the Development of Diabetes- Induced Nephropathy. J Diabetes Metab S9: 004. doi:10.4172/2155-6156.S9-004

Copyright: $\odot 2013$ Sharma V, et al. This is an open-access article distributed unde the terms of the Creative Commons Attribution License, which permits unrestricted use, distribution, and reproduction in any medium, provided the original author and source are credited. 


\section{Polyol pathway}

The polyol pathway consists of two enzymes. The first enzyme, Aldose Reductase (AR), reduces glucose to sorbitol with the aid of its co-factor NADPH, and the second enzyme, sorbitol dehydrogenase (SDH), with its co-factor $\mathrm{NAD}^{+}$, converts sorbitol to fructose, a process that increases the ratio of NADH/NAD and may result in both oxidative stress and activation of protein kinase C [12]. Fructose and its metabolites fructose-3-phosphate and 3-deoxyglucosone are more potent nonenzymatic glycation agents than glucose, Sorbitol may interfere with the uptake and metabolism of myo-inositol [13] . The physiological role of the AR pathway remains largely unknown. However, AR, sorbitol and myo-inositol are thought to play a role in the osmoregulation of the kidney [14]. Consumption of NADPH by AR results in the depletion of the levels of NADPH. This NADPH also acts as a cofactor for glutathione reductase, which reduces oxidized glutathione into reduced glutathione [2]. Excess sorbitol is oxidated to fructose. The flux of glucose through the polyol pathway would increase Advance Glycation End Products (AGE) formation. AGES, as well as binding of AGE to their receptors, are known to cause oxidative stress [15].

\section{Age pathways}

AGEs accumulate at site of microvascular injury in diabetes, including the kidney [16], the retina and within the vasculature [17]. Their importance as downstream mediators of tissue injury in diabetic kidney disease is demonstrated by animal studies using inhibitors of advanced glycation to retard the development of nephropathy without directly influencing glycemic control [18].

AGE receptors are present on various renal cell types2 including proximal tubular cells, mesangial cells, and podocytes [19]. AGE promote activation and expression of IL-6 and TGF $\beta 1$ via NF-kBdependent pathways [20]. The proximal tubule is the main site for reabsorption of filtered AGEs [21]. TGF- $\beta 1$ expression is closely linked to accumulation of AGEs in the kidney [22]. AGEs are thought to lead to the transcriptional up-regulation of TGF- $\beta 1$, possibly via PKC or oxidative stress. In experimental diabetes, oxidative stress is increased in proportion to the accumulation of AGEs [23]. AGEs can also lead to enhanced formation of free radicals both directly through catalytic sites in their molecular structure [24] and via stimulation of membrane bound $\mathrm{NAD}(\mathrm{P}) \mathrm{H}$ oxidase through the RAGE receptor and depletion of cellular antioxidant systems, such as glutathione peroxidase [25]. Mitochondrial dysfunction induced by AGEs and carbonyl intermediates may also contribute to the generation of superoxide [26]. AGE contribute to the release of proinflamatory cytokine and expression of growth factor and adhesion molecule such as VEGF and CTGF, TGF- $\beta 1$, IGF-1, PDGF, TNF- $\alpha$, IL-1 $\beta$, and IL-6 [20,27].

\section{Protein kinase $\mathrm{C}$ pathway}

PKC has eleven isoforms. Nine PKCs are activated by DAG, which is formed from excess glyceraldehyde- 3-phosphate. Increased glucose concentration results in increase amount of DAG, which activates PKC. PKC activation leads to changes in renal blood flow [28], by decreasing production of NO [29], mesangial expansion, albuminuria and increases GFR, increases pro-inflammatory gene expression and vascular permeability in several models of experimental diabetes [30]. PKC activation may be responsible for the increased expression of ECM molecules both directly and through TGF- $\beta 1$ overexpression. The capacity of active PKC to induce the formation of the transcription factor AP-1 is believed to be the major underlying mechanism of this combined induction of TGF- $\beta 1$ and ECM protein genes. In the glomeruli, DAG levels are increased and PKC is activated [31]. Downstream of DAG-sensitive PKC isozymes is their activation of mitogen activated protein kinases (ERK) 1/2, which are essential for mesangial cell growth and enhanced gene expression, including growth factors and extracellular matrix proteins [32]. ERK1/2 protein expression is unchanged but its activity is significantly increased through PKC dependent manner in mesangial cell and glomeruli. ET-1 stimulated collagen IV expression is also dependent on the activation of ERK1/2 through PKC activation [33].

\section{Hexosamine Pathway}

The hexosinase converts fructose-6-phosphate into glucosamine6-phosphate. Glutamine: Fructose-6-Phosphateamidotransferase (GFAT) is the rate-limiting enzyme of this pathway. Both high glucose and Ang II activates the GFAT promoter in mesangial cells [34] and this is a further mechanism that may enhance flux through the hexosinase. Overexpression of GFAT in MC leads to enhanced both TGF- $\beta$ and fibronectin expression [35]. Furthermore, high glucoseinduced TGF- $\beta 1$ and ECM production appear, at least in part, mediated by the hexosinase because they are significantly reduced by the GFAT inhibitor azaserine [36]. The mechanism by which increased flux through the HBSP induced gene transcription is uncertain, but it has been proposed that $\mathrm{N}$-acetylglucosamine may covalently modify transcription factors and signalling molecules, thus altering their activity. An increased flux through this path-way is associated with PKC activation, increased TGF- $\beta$ expression and ECM production, all of which are associated with the development of DN [37]. In addition, TGF- $\beta$ closely interacts with the RAS and PKC activity and their interplay could be central in the development of DN [38].

\section{Activation of Janus kinase (JAK)/STAT Pathway by Reactive Oxygen Species}

High glucose enhances ANG II induced activation of the JAK/ STAT pathway [39]. The JAK proteins are a family of cytosolic tyrosine kinases, which originally were thought to be coupled exclusively to cytokine receptors, such as those for the interleukins and interferons. The family contains four members (JAK1, JAK2, JAK3, and TYK2). In response to ligand binding to cytokine receptors, these JAK tyrosine kinases associate with, tyrosine-phosphorylate, and activate the cytokine receptor itself. Once activated, JAKs also tyrosines-phosphorylates and activate other signaling molecules, including the STAT family of nuclear transcription factors after binding of the STATs to the receptor [40]. Thus the JAK/STAT pathway is an important link between cell surface receptors and nuclear transcriptional events leading to cell growth. The mechanism(s) by which high glucose promotes JAK2 activation may be related to activation of JAK2 by ROS, and ROS are induced by high glucose in glomerular mesangial cells. It has shown that ROS stimulate the activity of JAK2 in fibroblasts. It have been shown that high glucose, via the polyol pathway, induces a rapid increase in intracellular ROS, such as $\mathrm{H}_{2} \mathrm{O}_{2}$, which stimulates intracellular signaling events similar to those activated by ANG II, including phosphorylation of growth promoting kinases such as JAK2 [41]. The polyol pathway generates ROS $\left(\mathrm{H}_{2} \mathrm{O}_{2}\right.$ and $\left.\mathrm{O}^{2}-\right)$, which can then act as signaling mediators in the activation of downstream mitogenic pathways, such as the JAK/ STAT cascade [42]. It has been shown that high glucose, via the polyol pathway, induces a rapid increase in intracellular ROS, such as $\mathrm{H}_{2} \mathrm{O}_{2}$, which stimulates intracellular signaling events similar to those activated by ANG II, including phosphorylation of growth promoting kinases such as JAK2 [43]. 


\section{NADPH Oxidase in Diabetic Nephropathy}

NADPH is formed during glycolysis or oxidative phosphorylation and exerts antioxidant activity by regenerating glutathione [44]. Glutathione act as important intracellular antioxidant by reacting with ROS and organic peroxides [45]. Thus antioxidant defense system will reduce with the reduction in the level of NADPH. In renal vessels, macula densa, thick ascending limb of loop of Henle, distal tubules, collecting ducts, interstitial fibroblasts and un glomerular podocyte and mesangial cells, the enzyme NADPH oxidase is a significant source of production of superoxide radical. For activation of NADPH oxidase, assembly of the subunits and translocation of p47phox to the membrane is necessary. NADPH oxidase generated superoxide radicals can react with $\mathrm{NO}$ forming peroxynitrite, which is a potent oxidant and nitrosylating agent. Furthermore, this reaction can cause NO deficiency. NO normally regulates tubuloglomerular feed back and renal blood flow, and is involved in regulation of natriuresis. The NO deficiency can be worsened by the fact that oxidative stress promotes activation of vasoconstrictors. Thus, NO deficient animal models develop glomerulosclerosis and proteinuria, as well as hypertension and renal failure [46]. Expression of p47phox is increased in podocytes, glomeruli, cortical distal tubules, loop of Henle and medullary collecting ducts in diabetic rats [47]. Further NADPH oxidase inhibitor, apocyanin decreases the expression of gp91phox and activation of p47phox in diabetic rats [48]. Furthermore, increased NADPH oxidase activity will decrease NADPH/NADP+ ratio, causing oxidative stress by the TCA cycle enzyme complex $\alpha$-ketoglutarate dehydrogenase [49]. However, NOX 4 expression was found abundantly in distal tubular cells [50]. High glucose or free fatty acid [51], oxidized LDL, hyperlipidemia [52], AngII in mesangial cell and endothelial cells are the potent activators of NADOH oxidase. Further, activation of NADPH oxidase causes an increase in ROS production. Furthermore, increased superoxide produced within the glomerular microcirculation decreases NO bioactivity on mesangial contraction and arteriolar tone and may contribute to many of the renal hemodynamic and vascular abnormalities in diabetic nephropathy [53].

\section{Growth Factors and Cytokines}

Several growth factors, cytokines, chemokines and vasoactive agents have been implicated in pathogenesis of diabetic nephropathy. TGF- $\beta$, a fibrotic cytokine, plays a central role in the development of renal hypertrophy and accumulation of ECM componenets [54]. In addition, there is increased infilteration of monocytes and macrophages into glomeuli early in diabetes. The release of growth factors and cytokines from these monocytes and macrophages (interlukin-8, monocyte chemotactic peptide-1 etc.) may contribute to promotion of glomerular growth.

There is increasing evidence that intrarenal renin-angiotensin system is activated in diabetic nephropathy [55]. There is enhanced expression of Ang II receptors and deceased degradation of Ang II thereby increasing the local effects of Ang II [56] which acts in synergy with hyperglycemia in stimulating free radicals, renal hypertrophy and synthesis of ECM proteins. Other growth factors which are involved in the development of diabetic nephropathy are Vascular Endothelial Growth Factor (VEGF), Platelet Derived Growth Factor (PDGF), Connective Tissue Growth Factor (CTGF), and Insulin-Like Growth Factor (IGF) [57].

\section{VEGF in Diabetic Nephropathy}

Vascular Endothelial Growth Factor (VEGF) is an attractive candidate to function as a mediator of endothelial dysfunction in diabetes. Under physiological conditions, VEGF is produced in kidney by glomerular epithelial cells, but mesangial and tubular epithelial cells do not normally produce this growth factor. It was demonstrated that during hyperglycemia, overexpression of VEGF occurs through PKC activation [58]. Further, TGF- $\beta 1$ which is over expressed in kidney also enhances VEGF expression [59]. Moreover, glomerular permeabilization by VEGF might induce both albuminuria and increased mesangial traffic of growth factors from the circulating blood. Hyperglycaemia increases VEGF excretion in the mesangial cell and podocyte via pathways involving $\mathrm{PKC}$ and extracellular signalregulated kinase (ERK) [60]. Receptors for VEGF in the glomerulus are found in the endothelial cells and it is thought that this growth factor increases the permeability of the glomerular endothelium and is therefore responsible for the hyperfiltration seen in early diabetic nephropathy. Also mechanical stretch mimicking the shear stress caused by hyperfiltration and increased glomerular pressure increased the excretion of VEGF in the mesangial cells. In a study demonstrating this effect it seemed that the effects of shear stress in mesangial cells are mediated via a pathway dependent on PKC and Protein Tyrosine Kinase (PTK) since the combined inhibition of these enzymes completely prevented the increased VEGF excretion in an in vitro experiment [61]. However, MC can also produce VEGF [62] and express VEGF receptors both in vitro and in pathological conditions [63]. Furthermore, VEGF binding to its receptors on MC induces both cell proliferation and collagen expression, providing a possible mechanism by which VEGF may contribute to glomerular hypertrophy/sclerosis [64]. In addition, VEGF potentially stimulate eNOS expression and activity in endothelial cells [65].

\section{TGF- $\beta 1$ in Diabetic Nephropathy}

The TGF- $\beta$ seems to play a central role as a mediator in the pathologic changes in the glomerulus. It has been shown that the AGE formation, PKC activation, angiotensin II, and shear stress increase TGF- $\beta$ expression [66]. TGF- $\beta$ is a potent growth factor promoting the deposition of ECM components, such as collagen I, IV and fibronectin. This leads to, the histologically evident glomerular expansion and thickening of the basement membrane. The effects of TGF- $\beta$ are mediated by the TGF- $\beta$ receptor type II [67], while the Smad pathway is the downstream intracellular signaling pathway involved in TGF- $\beta$ signaling [68]. This cytokine play a central role in the development of renal hypertrophy and accumulation of ECM components in diabetes [69]. During hyperglycemia, mesangial and proximal tubular cells synthesise more TGF- $\beta$ than control [70]. In addition, it has been demonstrated that intracellular glucosamine production resulting from glucose metabolism is responsible for the increased TGF- $\beta 1$ production in mesangial cells. Several vasoactive factors such as AngII, thromboxane [71] \& endithelin-1 [72] may exert part of their growthstimulating and profibrogenic action in diabetic renal diseases to the secondary induction of TGF- $\beta$. Furthermore non-enzymatic glycation reactions leading to AGE [73], as well as the early Amatori glucose adducts in proteins such as serum albumin have [74] been shown to stimulate renal expression of TGF- $\beta$. Amadori glucose adducts in albumin also increase expression of TGF- $\beta$ type II receptors m-RNA and protein levels in mesangial cells [75].

\section{PDGF in Diabetic Nephropathy}

The platelet derived growth factor beta (PDGF- $\beta$ ) is also involved in the histological alterations in the glomerulus. Under high glucose concentrations the PDGF- $\beta$ growth factor and the corresponding 
Citation: Sharma V, Sharma PL (2013) Role of Different Molecular Pathways in the Development of Diabetes- Induced Nephropathy. J Diabetes Metab S9: 004. doi:10.4172/2155-6156.S9-004

Page 4 of 7

receptor are upregulated in the mesangial cell leading to later increase in TGF- $\beta$ expression [76].

\section{Role of Oxidative Stress in Diabetic Nephropathy}

Hyperglycemia-induced oxidative stress has been suggested as the unifying mechanism causing the cell damage seen in diabetic complications [2]. Oxidative stress plays an important role in pathological changes of the kidney [77]. Oxidative stress occurs due to an imbalance between Reactive Oxygen Species (ROS) and intracellular antioxidants [78]. Further, it has been suggested that hyperglycemia

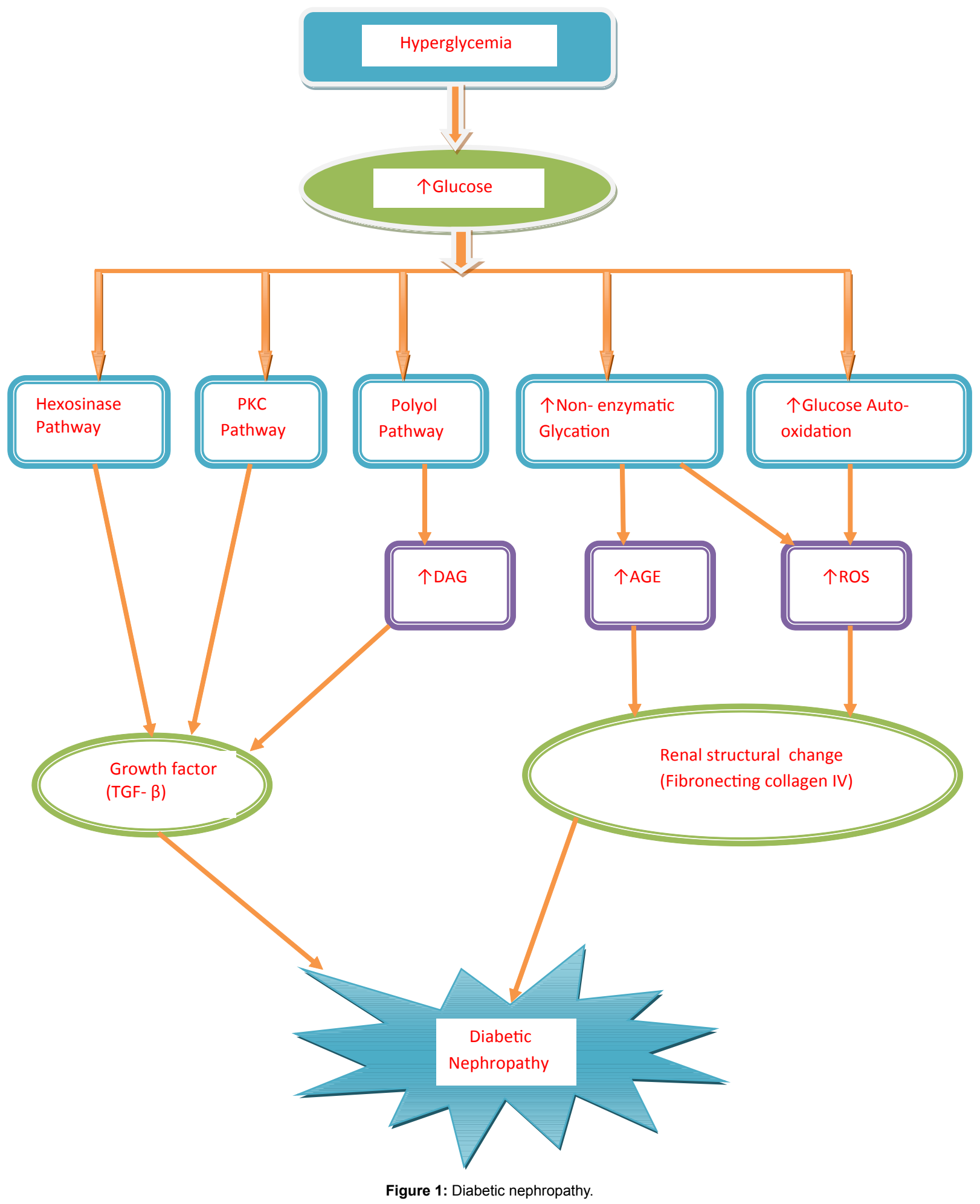


induced overproduction of superoxide by mitrochondrial electron transfer chain is the major molecular mechanisms for diabetes. Furthermore, increased NADPH oxidase activity leads to production of ROS in diabetic nephropathy [45]. Moreover, activation of PKC pathway leads to the production of ROS in diabetes which is attenuated by PKC inhibitors. In addition, it has been reported that, ROS activates (PKC, MAPK, JAK/STAT) and transcription factors (NF-kb, AP-1 and SP-1) and upregulates TGF- $\beta 1$ and fibronectin levels leading to accumulation of ECM in diabetic kidney. The current understanding is about the nonphagocyte NADPH oxidase at both structural and biochemical levels and the possible role in diabetic nephropathy. It has been demonstrated that PKC is actively involved in high glucose and free fatty acid-induced activation of NADPH oxidase [45]. High glucose, free fatty acid and phorbol ester-induced ROS generation was effectively inhibited by PKC inhibitors. Evidences suggested that ROS-regulated signaling pathways lead to Extracellular Matrix (ECM) deposition in diabetic kidney. ROS generated by high glucose levels activate signal transduction cascade (PKC, MAPK, and JAK/STAT) and transcription factors (NF-kB, AP-1, and Sp1) and upregulate TGF- $\beta 1$ and fibronectin in renal cells, and antioxidants effectively inhibit high glucose induced activation. It has been demonstrated that, in addition to upregulation of ECM synthesis, ROS play an important role in ECM degradation and epithelial-mesenchymal transition in tubular epithelial cells leading to glomerular mesangial and tubulointerstitial expansion [79]. It has been demonstrated that dichlorofluorescein sensitive ROS are increased in the glomeruli isolated from streptozotocin-diabetic rats, providing a direct evidence of increased ROS in diabetic glomeruli [41]. AGE are known to have a wide range of chemical, cellular, and tissue effects implicated in the development and progression of diabetic nephropathy. AGE generate ROS directly or through receptor for AGE, whereas ROS, in turn, promote formation of AGE. It has been demonstrated that AGE play an important role in diabetic nephropathy [80]. It has been demonstrated that over expression of receptor $r$ for AGE (RAGE) exaggerates nephropathy and retinopathy of diabetic mice, which are inhibited by inhibition of AGE formation. Antioxidant effectively inhibit high glucose induced TGF- $\beta$ and fibronectin upregulation [81] and reduces the oxidative stress by increasing the levels of intracellular antioxidants such as superoxide dismutase, catalase etc (Figure 1).

\section{Mitochondrial Electron Transport System (ETS)}

The mitochondrial ETS has long been known to be capable of generating ROS upto $2 \%$ of the total mitochondrial $\mathrm{O}_{2}$ consumption goes towards the production of ROS [82]. The specific species generated appear to be $\mathrm{O}^{2-}$ following its dismutation, $\mathrm{H}_{2} \mathrm{O}_{2}$. The production of ROS by mitochondria can involve NADH-coenzyme Q (complex I), succinate-coenzyme Q (complex II) and coenzyme $\mathrm{Q} \mathrm{H}_{2}$-cytochrome $\mathrm{c}$ reductases (complex III). A nonheme $\mathrm{Fe}^{+}$protein appear to be involved in the transfer of electrons to oxygen at each site. Most of this transfer is tightly coupled but a small amount of leakage occurs, primarily from NADH-coenzyme Q reductase complex and from autooxidation of coenzyme $\mathrm{Q}$ itself. Ubisemiquinone and ubiquinol have been proposed as the main sources of mitochondrial $\mathrm{O}^{2-}$ by participating in auto-oxidation reaction [83]. When the electrochemical potential difference generated by the proton gradient is high (such as in high glucose states), the life of superoxide-generating electron transport intermediates, such as ubisemiquinone, is prolonged. This occurs because the activity of the respiratory chain complexes as proton pumps is inherently governed by the transmembrane proton gradient $(\Delta \mathrm{pH})$ and the membrane potential $(\Delta ¥ \mathrm{mt})$. When sufficiently high,
$\Delta \mathrm{pH}$ and $\Delta ¥ \mathrm{mt}$ inhibit the proton pumps [84]. It is evident that each of the ROS-generating sites has a different redox potential, and thus each will respond differently to changes in $\Delta \mathrm{pH}$ and $\Delta ¥ \mathrm{mt}$, resulting in a complex regulation of ROS generation by these membrane gradients. There appears to be a threshold value above which even a small increase in $\Delta ¥ \mathrm{mt}$ gives rise to a large stimulation of superoxide production by mitochondria [85]. Overall, most bioenergetic effectors, via their effects on $\Delta \mathrm{pH}$ and $\Delta ¥ \mathrm{mt}$, can modulate mitochondrial ROS generation. In isolated mitochondria, dissipation of membrane potential by chemical uncouplers, free fatty acids, or the presence of ADP decreases the rate of ROS generation.

Uncoupling Proteins (UCPs) are members of a family of nuclearencoded mitochondrial carriers, which act as proton carrier proteins in the mitochondrial inner membrane. Further, these proteins facilitate the proton leak across the membrane and able to modulate the coupling between the respiratory electron transport chain and ATP synthesis. Furthermore, UCP-induced proton leakiness causes partial depolarization of the mitochondrial transmembrane potential [86]. However, the UCP subtypes, UCP-1, UCP-2, and UCP-3, differ with respect to tissue distribution and probably also function. Increased induction of UCP-1 leads to thermogenesis. However, the functions of UCP-2 and UCP-3 are still unclear but are believed to cause a mild uncoupling of respiration that governs mitochondrial membrane potential and the accumulation of oxygen radicals and/or control of the $\mathrm{NAD}^{+} / \mathrm{NADH}$ ratio. It has been demonstrated that UCP-2 expression is inversely correlated with the level of ROS generation by respiring mitochondria [87]. During diabetes, overexpression of UCPs in cultured neurons blocks glucose-induced programmed cell death by preventing mitochondrial hyperpolarization and formation of ROS This suggests a central role for UCPs in the regulation of mitochondrial membrane hyperpolarization and ROS formation in glucose-mediated neuronal injury.

\section{Acknowledgments}

I am highly thankful to Prof. P.L. Sharma for his critical review, remarks, and suggested corrections in the paper.

\section{References}

1. Ohashi N, Urushihara M, Satou R, Kobori H (2010) Glomerular angiotensinogen is induced in mesangial cells in diabetic rats via reactive oxygen species--ERK JNK pathways. Hypertens Res 33: 1174-1181.

2. Alter ML, Ott IM, von Websky K, Tsuprykov O, Sharkovska Y,et al. (2012) DPP 4 inhibition on top of angiotensin receptor blockade offers a new therapeutic approach for diabetic nephropathy. Kidney Blood Press Res 36: 119-130.

3. Jankun J (2012) Challenging delivery of VLHL NS plasminogen activator inhibitor-1 by osmotic pumps in diabetic mouse: A case report. Exp Ther Med 4: 661-664.

4. Hao HH, Shao ZM, Tang DQ, Lu Q, Chen X, et al. (2012) Preventive effects of rutin on the development of experimental diabetic nephropathy in rats. Life Sci 91: 959-967.

5. Bonventre JV (2012) Can we target tubular damage to prevent renal function decline in diabetes? Semin Nephrol 32: 452-462.

6. Romesh Khandori (2000) Non-renal replacement modalities in treatment of diabetic nephropathy. Int J Diab Dev Countries 20: 127-132.

7. Ojima A, Ishibashi Y, Matsui T, Maeda S, Nishino Y, et al. (2012) Glucagonlike peptide-1 receptor agonist inhibits asymmetric dimethylarginine generation in the kidney of streptozotocin-induced diabetic rats by blocking advanced glycation end product-induced protein arginine methyltranferase-1 expression. Am J Pathol 182: 132-141.

8. Riedl E, Pfister F, Braunagel M, Brinkkötter P, Sternik P, et al. (2011) Carnosine prevents apoptosis of glomerular cells and podocyte loss in STZ diabetic rats. Cell Physiol Biochem 28: 279-288. 
Citation: Sharma V, Sharma PL (2013) Role of Different Molecular Pathways in the Development of Diabetes- Induced Nephropathy. J Diabetes Metab S9: 004. doi:10.4172/2155-6156.S9-004

9. Juan YS, Chuang SM, Long CY, Lin RJ, Liu KM, et al. (2012) Protein kinase $\mathrm{C}$ inhibitor prevents renal apoptotic and fibrotic changes in response to partial ureteric obstruction. BJU Int 110: 283-292.

10. Titan SM, Vieira JM Jr, Dominguez WV, Moreira SR, Pereira AB, et al. (2012) Urinary MCP-1 and RBP: independent predictors of renal outcome in macroalbuminuric diabetic nephropathy. J Diabetes Complications 26: 546553

11. Zhou Y, Liao Q, Luo Y, Qing Z, Zhang Q, et al. (2012) Renal protective effect of Rosa laevigata Michx. by the inhibition of oxidative stress in streptozotocininduced diabetic rats. Mol Med Rep 5: 1548-1554.

12. Ramana KV (2011) ALDOSE REDUCTASE: New Insights for an Old Enzyme. Biomol Concepts 2: 103-114.

13. Tadege M, Mysore KS (2011) Tnt1 retrotransposon tagging of STF in Medicago truncatula reveals tight coordination of metabolic, hormonal and developmental signals during leaf morphogenesis. Mob Genet Elements 1: 301-303.

14. Kage-Nakadai E, Uehara T, Mitani $\mathrm{S}$ (2011) $\mathrm{H}+$ /myo-inositol transporter genes, hmit-1.1 and hmit-1.2, have roles in the osmoprotective response in Caenorhabditis elegans. Biochem Biophys Res Commun 410: 471-477.

15. Yamagishi S, Maeda S, Matsui T, Ueda S, Fukami K, et al. (2012) Role of advanced glycation end products (AGEs) and oxidative stress in vascular complications in diabetes. Biochim Biophys Acta 1820: 663-671.

16. Liu JP, Feng L, Zhu MM, Wang RS, Zhang MH, et al. (2012) The in vitro protective effects of curcumin and demethoxycurcumin in Curcuma longa extract on advanced glycation end products-induced mesangial cell apoptosis and oxidative stress. Planta Med 78: 1757-1760.

17. Puddu A, Sanguineti R, Durante A, Nicolò M, Viviani GL (2012) Vascular endothelial growth factor-C secretion is increased by advanced glycation endproducts: possible implication in ocular neovascularization. Mol Vis 18: 25092517

18. Thomas MC, Forbes JM, Cooper ME (2005) Advanced glycation end products and diabetic nephropathy. Am J Ther 12: 562-572.

19. Wang W, Wang Y, Long J, Wang J, Haudek SB, et al. (2012) Mitochondria fission triggered by hyperglycemia is mediated by ROCK1 activation in podocytes and endothelial cells. Cell Metab 15: 186-200.

20. Bonventre JV (2012) Can we target tubular damage to prevent renal function decline in diabetes? Semin Nephrol 32: 452-462.

21. Ishibashi Y, Yamagishi S, Matsui T, Ohta K, Tanoue R, et al. (2012) Pravastatin inhibits advanced glycation end products (AGEs)-induced proximal tubular cell apoptosis and injury by reducing receptor for AGEs (RAGE) level. Metabolism 61: 1067-1072.

22. Lee SH, Kim YS, Lee SJ, Lee BC (2011) The protective effect of Salvia miltiorrhiza in an animal model of early experimentally induced diabetic nephropathy. J Ethnopharmacol 137: 1409-1414.

23. Ha Y, Saul A, Tawfik A, Zorrilla EP, Ganapathy V, et al. (2012) Diabetes accelerates retinal ganglion cell dysfunction in mice lacking sigma receptor 1 . Mol Vis 18: $2860-2870$

24. Drobyshevsky A, Yu L, Yang Y, Khalid S, Luo K, et al. (2012) Antenatal insults modify newborn olfactory function by nitric oxide produced from neuronal nitric oxide synthase. Exp Neurol 237: 427-434.

25. Serpillon S, Floyd BC, Gupte RS, George S, Kozicky M, et al. (2009) Superoxide production by $\mathrm{NAD}(\mathrm{P}) \mathrm{H}$ oxidase and mitochondria is increased in genetically obese and hyperglycemic rat heart and aorta before the development of cardiac dysfunction. The role of glucose-6-phosphate dehydrogenase-derived NADPH. Am J physiol heart Circ Physiol 297: H153-H162.

26. Liu IM, Tzeng TF, Liou SS, Chang CJ (2011) Angelica acutiloba root alleviates advanced glycation end-product-mediated renal injury in streptozotocindiabetic rats. J Food Sci 76: H165-174.

27. Lattke M, Magnutzki A, Walther P, Wirth T, Baumann B (2012) Nuclear factor $\hat{1}^{\circ} \mathrm{B}$ activation impairs ependymal ciliogenesis and links neuroinflammation to hydrocephalus formation. J Neurosci 32: 11511-11523.

28. Song J, Eyster KM, Kost CK Jr, Kjellsen B, Martin DS (2010) Involvement of protein kinase $\mathrm{C}-\mathrm{CPI}-17$ in androgen modulation of angiotensin II-renal vasoconstriction. Cardiovasc Res 85: 614-621.

29. Schwartz IF, Grupper A, Soetendorp H, Hillel O, Laron I, et al. (2012) Attenuated glomerular arginine transport prevents hyperfiltration and induces HIF-1 $1 \pm$ in the pregnant uremic rat. Am J Physiol Renal Physiol 303: F396-404.
30. Cui B, Sun JH, Xiang FF, Liu L, Li WJ (2012) Aquaporin 4 knockdown exacerbates streptozotocin-induced diabetic retinopathy through aggravating inflammatory response. Exp Eye Res 98: 37-43.

31. Gal N, Kolusheva S, Kedei N, Telek A, Naeem TA, et al. (2011) N-methylsubstituted fluorescent DAG-indololactone isomers exhibit dramatic differences in membrane interactions and biological activity. Chembiochem 12: 2331-2340.

32. Ko B, Cooke LL, Hoover RS (2011) Parathyroid hormone (PTH) regulates the sodium chloride cotransporter via Ras guanyl releasing protein 1 (Ras-GRP1) and extracellular signal-regulated kinase (ERK)1/2 mitogen-activated protein kinase (MAPK) pathway. Transl Res 158: 282-289.

33. Blaes N, Pécher C, Mehrenberger M, Cellier E, Praddaude F, et al. (2012) Bradykinin inhibits high glucose- and growth factor-induced collagen synthesis in mesangial cells through the B2-kinin receptor. Am J Physiol Renal Physio 303: F293-303.

34. Singh VP, Baker KM, Kumar R (2008) Activation of the intracellular reninangiotensin system in cardiac fibroblasts by high glucose: role in extracellular matrix production. Am J Physiol Heart Circ Physiol 294: H1675-1684.

35. Zheng JM, Zhu JM, Li LS, Liu ZH (2008) Rhein reverses the diabetic phenotype of mesangial cells over-expressing the glucose transporter (GLUT1) by inhibiting the hexosamine pathway. Br J Pharmacol 153: 1456-1464.

36. Bran GM, Goessler UR, Schardt C, Hormann K, Riedel F, et al. (2010) Effect of the abrogation of TGF-beta1 by antisense oligonucleotides on the expression of TGF-beta-isoforms and their receptors I and II in isolated fibroblasts from keloid scars. Int J Mol Med 25: 915-921.

37. Hao HH, Shao ZM, Tang DQ, Lu Q, Chen X, et al. (2012) Preventive effects of rutin on the development of experimental diabetic nephropathy in rats. Life Sci 91: 959-967.

38. Lee M (2008) Differential physiological effects of Raf-1 kinase pathways linked to protein kinase $\mathrm{C}$ activation depending on the stimulus in $\mathrm{v}-\mathrm{H}$-ras-transformed cells. Cancer Res Treat 40: 39-44.

39. Marrero MB, Banes-Berceli AK, Stern DM, Eaton DC (2006) Role of the JAK STAT signaling pathway in diabetic nephropathy. Am J Physiol Renal Physio 290: F762-768.

40. Nam S, Wen W, Schroeder A, Herrmann A, Yu H, et al. (2012) Dual inhibition of Janus and Src family kinases by novel indirubin derivative blocks constitutivelyactivated Stat3 signaling associated with apoptosis of human pancreatic cancer cells. Mol Oncol S1574-7891: 122-126.

41. Wang F, Tian F, Whitman SA, Zhang DD, Nishinaka T, et al. (2012) Regulation of transforming growth factor i $^{2} 1$-dependent aldose reductase expression by the Nrf2 signal pathway in human mesangial cells. Eur J Cell Biol 91: 774-781.

42. Park SK, Dahmer MK, Quasney MW (2012) MAPK and JAK-STAT signaling pathways are involved in the oxidative stress-induced decrease in expression of surfactant protein genes. Cell Physiol Biochem 30: 334-346.

43. Shaw S, Wang X, Redd H, Alexander GD, Isales CM, et al. (2003) High glucose augments the angiotensin II-induced activation of JAK2 in vascular smooth muscle cells via the polyol pathway. J Biol Chem 278: 30634-30641.

44. Cheung EC, Ludwig RL, Vousden KH (2012) Mitochondrial localization of TIGAR under hypoxia stimulates HK2 and lowers ROS and cell death. Proc Natl Acad Sci U S A 109: 20491-20496.

45. Jomova K, Jenisova Z, Feszterova M, Baros S, Liska J, et al. (2011) Arsenic: toxicity, oxidative stress and human disease. J Appl Toxicol 31: 95-107.

46. van Koppen A, Joles JA, Bongartz LG, van den Brandt J, Reichardt HM, et al. (2012) Healthy Bone Marrow Cells Reduce Progression of Kidney Failure Better Than CKD Bone Marrow Cells in Rats With Established Chronic Kidney Disease. Cell Transplant 21: 2299-2312.

47. Sands JM, Layton HE (2009) The physiology of urinary concentration: an update. Semin Nephrol 29: 178-195.

48. Mayhan WG, Arrick DM, Sharpe GM, Patel KP, Sun H (2006) Inhibition of $\mathrm{NAD}(\mathrm{P}) \mathrm{H}$ oxidase alleviates impaired NOS-dependent responses of pial arterioles in type 1 diabetes mellitus. Microcirculation 13: 567-575.

49. Faix B, Radchuk V, Nerlich A, Hümmer C, Radchuk R, et al. (2012) Barley grains, deficient in cytosolic small subunit of ADP-glucose pyrophosphorylase, reveal coordinate adjustment of $\mathrm{C}: \mathrm{N}$ metabolism mediated by an overlapping metabolic-hormonal control. Plant J 69: 1077-1093.

50. Gill PS, Wilcox CS (2006) NADPH oxidases in the kidney. Antioxid Redox Signal 8: 1597-1607. 
Citation: Sharma V, Sharma PL (2013) Role of Different Molecular Pathways in the Development of Diabetes- Induced Nephropathy. J Diabetes Metab S9: 004. doi:10.4172/2155-6156.S9-004

Page 7 of 7

51. Negami M, Takahashi E, Otsuka H, Moriyama K (2012) Prediction of homeostasis model assessment of insulin resistance in Japanese subjects. Tokai J Exp Clin Med 37: 102-106.

52. Jenkins NT, Landers RQ, Thakkar SR, Fan X, Brown MD, et al. (2011) Prior endurance exercise prevents postprandial lipaemia-induced increases in reactive oxygen species in circulating CD31+ cells. J Physiol 589: 5539-5553.

53. Dei Cas A, Gnudi L (2012) VEGF and angiopoietins in diabetic glomerulopathy: how far for a new treatment? Metabolism 61: 1666-1673.

54. López-Hernández FJ, López-Novoa JM (2012) Role of TGF-î ${ }^{2}$ in chronic kidney disease: an integration of tubular, glomerular and vascular effects. Cell Tissue Res 347: 141-154.

55. Urushihara M, Kobori H (2011) Angiotensinogen Expression Is Enhanced in the Progression of Glomerular Disease. Int J Clin Med 2: 378-387.

56. Wysocki J, Ye M, Rodriguez E, González-Pacheco FR, Barrios C, et al. (2010) Targeting the degradation of angiotensin II with recombinant angiotensinconverting enzyme 2: prevention of angiotensin II-dependent hypertension. Hypertension 55: 90-98.

57. Masoad RE, Ewais MM, Tawfik MK, Abd El-All HS (2012) Effect of mononuclea cells versus pioglitazone on streptozotocin-induced diabetic nephropathy in rats. Pharmacol Rep 64: 1223-1233.

58. Kumar B, Gupta SK, Srinivasan BP, Nag TC, Srivastava S, et al. (2012) Hesperetin ameliorates hyperglycemia induced retinal vasculopathy via antiangiogenic effects in experimental diabetic rats. Vascul Pharmacol 57: 201 207.

59. Li X, Hu J, Zhang Q, Sun X, Li S (2009) Urocortin 1 improves renal function in rats with streptozotocin-induced diabetes by inhibiting overproduction of TGFbeta 1 and VEGF. Br J Pharmacol 157: 994-1003.

60. Moriguchi S, Shioda N, Yamamoto Y, Fukunaga K (2010) Platelet-activating factor-induced synaptic facilitation is associated with increased calcium/ calmodulin-dependent protein kinase II, protein kinase $\mathrm{C}$ and extracellula signal-regulated kinase activities in the rat hippocampal CA1 region. Neuroscience 166: 1158-1166.

61. de Oliveira S, Silva-Herdade AS, Saldanha C (2008) Modulation of erythrocyte deformability by PKC activity. Clin Hemorheol Microcirc 39: 363-373.

62. Merkle M, Ribeiro A, Belling F, Mannell H, Krötz F, et al. (2012) Response of VEGF to activation of viral receptors and TNFÎ \pm in human mesangial cells. Mo Cell Biochem 370: 151-161.

63. Noghero A, Perino A, Seano G, Saglio E, Lo Sasso G, et al. (2012) Liver X receptor activation reduces angiogenesis by impairing lipid raft localization and signaling of vascular endothelial growth factor receptor-2. Arterioscler Thromb Vasc Biol 32: 2280-2288.

64. Sasaki M, Shikata K, Okada S, Miyamoto S, Nishishita S, et al. (2011) The macrophage is a key factor in renal injuries caused by glomerular hyperfiltration. Acta Med Okayama 65: 81-89.

65. Lee JH, Chun T, Park SY, Rho SB (2008) Interferon regulatory factor-1 (IRF1) regulates VEGF-induced angiogenesis in HUVECs. Biochim Biophys Acta 1783: $1654-1662$.

66. Mehta JL (2004) The role of LOX-1, a novel lectin-like receptor for oxidized low density lipoprotein, in atherosclerosis. Can J Cardiol 20 Suppl B: 32B-36B.

67. Abe $\mathrm{H}$ (2011) [Recent progress in understanding the molecular pathogenesis of diabetic nephropathy]. Rinsho Byori 59: 179-186.

68. Chen Z, Zhang D, Yue F, Zheng M, Kovacevic Z, et al. (2012) The iron chelators Dp44mT and DFO inhibit TGF- $\left.\right|^{2}$-induced epithelial-mesenchymal transition via up-regulation of N-Myc downstream-regulated gene 1 (NDRG1). J Biol Chem 287: 17016-17028.

69. Mariappan MM (2012) Signaling mechanisms in the regulation of renal matrix metabolism in diabetes. Exp Diabetes Res 2012: 749812

70. Phillips A, Janssen U, Floege J (1999) Progression of diabetic nephropathy.
Insights from cell culture studies and animal models. Kidney Blood Press Res 22: $81-97$

71. Osaki T, Azuma K, Kurozumi S, Takamori Y, Tsuka T, et al. (2012) Metabolomic analyses of blood plasma after oral administration of D-glucosamine hydrochloride to dogs. Mar Drugs 10: 1873-1882.

72. Hu Z, Ren L, Wang C, Liu B, Song G (2012) Effect of chenodeoxycholic acid on fibrosis, inflammation and oxidative stress in kidney in high-fructose-fed Wistar rats. Kidney Blood Press Res 36: 85-97.

73. Jung DH, Kim YS, Kim NH, Lee J, Jang DS, et al. (2010) Extract of Cassiae Semen and its major compound inhibit S100b-induced TGF-beta1 and fibronectin expression in mouse glomerular mesangial cells. Eur J Pharmacol 641: 7-14.

74. Li Q, Ye F, Shi Y, Zhang L, Wang W, et al. (2006) Nuclear translocation of SMAD3 may enhance the TGF-beta/SMADS pathway in high glucose circumstances. Transplant Proc 38: 2158-2160.

75. Wahab NA, Schaefer L, Weston BS, Yiannikouris O, Wright A, et al. (2005) Glomerular expression of thrombospondin-1, transforming growth factor beta and connective tissue growth factor at different stages of diabetic nephropathy and their interdependent roles in mesangial response to diabetic stimuli. Diabetologia 48: 2650-2660.

76. Zou L, Wang W, Xu Z, Zhang N, Jiang T (2012) Aldose reductase regulates platelet-derived growth factor-induced proliferation through mediating cell cycle progression in rat mesangial cells. Int J Mol Med 30: 409-416.

77. Fang D, Wan X, Deng W, Guan H, Ke W, et al. (2012) Fufang Xue Shuan Tong capsules inhibit renal oxidative stress markers and indices of nephropathy in diabetic rats. Exp Ther Med 4: 871-876.

78. Palacios HH, Yendluri BB, Parvathaneni K, Shadlinski VB, Obrenovich ME, et al. (2011) Mitochondrion-specific antioxidants as drug treatments for Alzheime disease. CNS Neurol Disord Drug Targets 10: 149-162.

79. Bai S, Zeng R, Zhou Q, Liao W, Zhang Y, et al. (2012) Cdc42-interacting protein-4 promotes TGF-li'1-induced epithelial-mesenchymal transition and extracellular matrix deposition in renal proximal tubular epithelial cells. Int $J$ Biol Sci 8: 859-869.

80. Lai YL, Aoyama S, Ohata M, Otsuka N, Shiokawa H, et al. (2012) Dysregulation of dimethylargininedimethylaminohydrolase/asymmetric dimethylarginine pathway in rat type II diabetic nephropathy. J Clin Biochem Nutr 51: 143-149.

81. Lin T, He F, Lei B (2012) [Expressions of adiponectin and its receptors in the retina of normal and type 1 diabetic mice]. Nan Fang Yi Ke Da Xue Xue Bao 32: $1543-1547$

82. Yang CA, Cheng CH, Lee JW, Lo CT, Liu SY, et al. (2012) Monomeric L-amino acid oxidase-induced mitochondrial dysfunction in Rhizoctonia solani Reveals a novel antagonistic mechanism of Trichoderma harzianum ETS 323. J Agric Food Chem 60: 2464-2471.

83. Samoilova RI, Crofts AR, Dikanov SA (2011) Reaction of superoxide radica with quinone molecules. J Phys Chem A 115: 11589-11593.

84. Nguyen TT, Ogbi M, Yu Q, Johnson JA (2010) Attenuation of the hypoxiainduced protein kinase Cdelta interaction with the 'd' subunit of F1Fo-ATP synthase in neonatal cardiac myocytes: implications for energy preservation and survival. Biochem J 429: 335-345.

85. Hashem FM, Shaker DS, Nasr M, Saad IE, Ragaey R (2011) Guar gum and hydroxy propyl methylcellulose compressed coated tablets for colonic drug delivery: in vitro and in vivo evaluation in healthy human volunteers. Drug Discov Ther 5: 90-95

86. Berardi MJ, Shih WM, Harrison SC, Chou JJ (2011) Mitochondrial uncoupling protein 2 structure determined by NMR molecular fragment searching. Nature 476: 109-113.

87. Qian S, Huo D, Wang S, Qian Q (2011) Inhibition of glucose-induced vascula endothelial growth factor expression by Salvia miltiorrhiza hydrophilic extract in human microvascular endothelial cells: evidence for mitochondrial oxidative stress. J Ethnopharmacol 137: 985-991. 